\title{
Responding to Enterprise Architecture Initiatives: Loyalty, Voice and Exit
}

\author{
Lena Hylving \\ RISE Viktoria AB, University of Gothenburg \\ lena.hylving@ri.se
}

\author{
Bendik Bygstad \\ University of Oslo \\ bendikby@ifi.uio.no
}

\begin{abstract}
Many large organizations have on-going Enterprise Architecture initiatives. Key aims include achieving more organizational agility, and to tidy up a messy portfolio of IT silo systems. A holistic approach to IT architecture has been an accepted strategy, but the results of these initiatives have been variable. An underresearched aspect is how different organizational units respond to the call for a holistic approach. In this study, we investigate how different stakeholders connected to three ongoing projects responded to the call for EA. With a qualitative approach, we identify three options of response to EA initiatives: (i) compliance with the EA strategy, (ii) loyal but isolated response, and (iii) rebel solutions. We argue for the need of a more nuanced repertoire of actions for dealing with $E A$, and show how these responses are useful for understanding and managing successful EA.
\end{abstract}

\section{Introduction}

Enterprise Architecture (EA) is a good idea in trouble [1]. The past decade, many organizations have been involved in large IT projects, aiming to restructure silo IT architectures, in order to offer better services. Since its introduction in the beginning of the 1990s EA has been hailed as a holistic and feasible approach for organizations with complex and fragmented IT portfolios [2, 3]. It has also been proposed as a means to increase organizational agility [4] and emphasis on organizational aspects has been highlighted [5].

However, the results have been less compelling. While there are some documented successes [6, 7], many EA initiatives have been disappointments: they are not necessarily outright failures, but they seem to go on forever, without concrete results. Limited understanding and/or lack of resources in EA projects are often root causes to problems [8]. In 2014 Jason Bloomberg asked in Forbes: "Is Enterprise Architecture
Completely Broken?" and commented; "Enterprise Architects have used various frameworks and other tools to document how their organization operates, often with meticulous detail. But to what end? (...). Common to most definitions is the notion that such architects must drive business transformation in their organizations. But the practice of EA has become all about documentation rather than effecting business change. (...) The field of Enterprise Architecture must itself transform into a new, Agile Architecture in order to drive digital transformation effectively in today's increasingly wired world" [1].

Is the idea of EA wrong, or is it the practical application of it that is the problem? One core issue, we think, is that organizations are not "architected"; rather they grow and change organically as they adapt to outer and inner pressures and changes $[9,10]$. IT architecture should be a means to enable this process, not hindering it or have an inertial effect; i.e. it should be flexible enough to include change, but stable enough to work as a foundation [11]. This is easier said than done, in particular because most large organizations have hundreds of IT systems that form the backbone of the business processes.

However, one way to advance seems to be to include the term agile. There are ambitious approaches that have been proposed, in the form of new frameworks, such as "Agile Architecture" [12] and "Software Architecture for Developers" [13]. But architectural design has an uneasy relationship with agile practices; unlike system functionality it cannot be divided into separate components or user stories.

Two aspects are lacking in these discourses. First, much of the EA literature assumes that EA is primarily about building new solutions, while in reality most organizations already have too many IT systems. The important architectural decisions of these existing systems were taken years ago and are difficult to change due to path-dependency [14]. Second, there is lack of an organizational perspective; after all, an organization is about the actions of its members. In order to improve $\mathrm{EA}$, it is not enough to discuss frameworks and 
technological solutions, but we must also understand the social practices of EA. Most normative literature assumes that organizational responses to EA is about being "compliant" (i.e. loyal) or "not compliant" (i.e. disloyal or incompetent) to decide plan and architecture [3]. We believe that this perspective is too limited, because there are many ways to respond to an architectural initiative. We therefor call for a more nuanced understanding of compliance. To develop our argument we build loosely on Hirschman's [15] term loyalty, voice and exit.

As a first step to limit this gap in EA research, we set out to investigate the interaction between EA governance and response. While EA governance necessarily is a centralized activity, the practical response to the holistic schemes is done in departments and projects. The practical response is not only the actual changes in systems and processes, but also the feedback of experiences and new insights. While everybody would agree that it is essential for organizations to learn from their experiences, researchers such as van der Raadt and van Vliet [16] have found that effective upward feedback is rare in EA initiatives. To further advance the understanding of EA as a phenomenon, and continue on van der Raadt and van Vliet's insights regarding communication and feedback connected to EA initiatives, we aim to answer the following question:

How do stakeholders, such as projects and other organizational groupings, respond to central EA initiatives, and what options do they have?

In this paper we adopt a practice lens [17] and conduct an in-depth investigation of EA governance and response in a large organization. Using Hirschman's [15] terms of loyalty, voice and exit as sensitizing concepts [18] we identify three different strategies for response, and discuss their significance for improving the iterative learning process connected to EA development. A theoretical implication of this study is that the EA research needs a more nuanced repertoire of actions for dealing with, and learning from, local responses. As for the industry, we suggest that feedback from stakeholders should be more actively nurtured and considered in EA initiatives.

\section{A brief overview of Enterprise Architecture Research}

Usually the foundation of EA is attributed to Zachman's [2] paper, where he called for a holistic approach while other point out the value of a central transformation governance [19]. The scope of the frameworks has increased significantly during the years; at the start a key objective for EA was to clean up the IT infrastructure, while business issues gradually have become more important. Accordingly, research was mainly normative the first years, but in the later years we have seen more empirical and critical contributions. There are a large number of frameworks, but we deal with only three of them in this paper.

The frameworks stream consists mainly of contributions from key actors, such as Zachman and the Open Group. While Zachman's framework primarily was ontology oriented and focused on classification, the Open Group's TOGAF quickly became the dominant framework, partly because it provided a full process for implementation and use. The current version is 9.1 and a significant number of the world's largest corporations are users. An influential contribution was the framework of Ross et al., [4], Enterprise Architecture as Strategy, which focused more on business perspectives, and established the operating model as a foundation.

The improvement stream consists of actors that are part of the EA community, but usually more empirically oriented. Tamm et al. [20] found that EA creates value through four factors; organizational alignment, information availability, resource portfolio optimization, and resource complementarity. The Enterprise Architecture Management (EAM) stream has identified four success factors; 'EAM product quality', 'EAM infrastructure quality', 'EAM service delivery quality', and 'EAM organizational anchoring' [21]. Recent insights by Röglinger et al [19] emphasize the importance of preparation before implementation. It has been highlighted that EA provides too little decision support [22] and Graves [23]) argued that the strong focus on structure should be complemented with a narrative perspective.

The term agile EA has been introduced as an alternative to the often slow and formal processes of EA and recent call for papers stress the importance of agility in relation to EA [24]. But already in 2013 Bloomberg [12]) argued that EA should learn from the agile thinking of modern project management and practices. An example was reported in Forbes in 2014, where the IT designer of Netflix, Adrian Cockcroft explained their development strategy: "Our architecture was changing faster than you can draw it," he pointed out. "As a result, it wasn't useful to try to draw it" [6]

The critical stream has focused on more fundamental problems with EA. Martin [25] found that implementation of EA is indeed challenging. In federated organizational structures, architectural principles tend to lose against short-term business concerns, and are thus basically ineffective. A deeper critique was voiced by Kemp and McManus [26], who found two fundamental problems; first, EA is based on a top-down strategy that assumes that it is analytically and managerially possible to control everything at the 
operative level. Second, the long-term view of EA is incompatible with a rapidly changing world.

\subsection{Communication in EA initiatives}

EA is supposed to facilitate communication between all affected resources, including external recourses [11]. However, EA initiatives are usually run in a top-down manner; a central team of enterprise architects run the process of developing and implementing the architecture, in co-operation with business managers and IT specialists [4]. In other words, EA as a product and process is a mean for communication for everyone involved and affected. However, it is often a homogenous central group of managers and architects developing the EA governance mechanisms (guidelines, principles, policies and so forth). Consequently, it is important for the EA team to communicate with all stakeholders to understand the context and requirements of the EA. Nevertheless, the normative EA literature assumes loyalty by all stakeholders. For instance, TOGAF recommends Project Impact Assessments and Architecture Compliance reviews to ensure compliance [3].

An interpretation of this is that the central team involved in the development of EA has a functional perspective of EA, while the resources using EA have a constructional perspective of EA. They both are complementary since the centralized team asks 'what is the architecture supposed to do' from a management perspective while the users asks 'how do we use the architecture' from a practical perspective[27]. Therefore, both the team developing the governance mechanisms and the people applying the mechanisms need to be involved in EA initiatives.

The main mediating mechanism in an EA initiative is considered to be communication [3, 4, 20] that connects EA initiatives and guidelines. However, EA communication is often described as a top-down, oneway communication where representatives of EA command and control how, why and what should be done. In particular, the normative framework, such as TOGAF [3] deal only superficially with the learning aspects of EA initiatives.

According to Crossan, et al. [28]) is a successful organizational change initiative dependent on establishing an organizational learning cycle i.e. a process where strategic initiatives are fed downwards in the organization, and experiences are fed upwards again, in order to facilitate learning. However, the learning cycle of downward and upward feedback is difficult in an EA context for two reasons. First, the link between the EA team and the projects often is thin, vague and vulnerable: a project has some key economic or organizational objectives, and EA compliance is not necessarily a priority $[25,29]$. Second, the meaning of "architecture" is quite different at EA and project level; at EA level architecture means a high-level view of the processes and technology of the whole enterprise. At the project level, however, architecture is about design choices related to systems and applications. Thus, the meaning of EA may be difficult to understand for projects, and the relevance of project experiences, accordingly, may be difficult to assess for the central EA team. Consequently, effective upward feedback is rare in EA initiatives [16].

\section{Analytical lens: Loyalty, Voice and Exit}

Our theoretical lens for developing a more nuanced understanding on how to improve Enterprise Architecture initiatives is Hirschman's work on loyalty, voice and exit. However, Hirschman's research contexts were firms and their relations to customers and members. In this context customers and members have three options, namely loyalty voice and exit, to respond to change. Hirschman's changes concerned higher price on a product or reduced quality. Depending on the changes a stakeholder can "make an attempt at changing the practices, policies, and outputs" [15]. The voice option is defined as "any attempt at all to change, rather than to escape from ... with the intention of forcing a change in management"[15]. Another option is exit. The result of exist can be "revenues drop, membership declines, and management is impelled to search for ways and means to correct whatever faults have led to exit"'[15]. A person may delay the exit option if she feels that the voice option is likely to be successful. The third option, loyalty, "can serve the socially useful purpose of preventing deterioration from becoming cumulative" says Hirschman [15] and can be defined as passively waiting for conditions to improve.

Hirschman's believed that the three responses influence, and are dependent on, each other in different ways. For example, he argues that "loyalty holds exit at bay and activates voice" [15] and that "the presence of loyalty makes exit less likely" [15]. These complex interactions and relations between exit, voice and loyalty are not applied in this study. Since our context is different we use Hirschmann's terms mainly as a sensitizing device [18]. In doing so we make two assumptions.

First, we take loyalty, voice and exit to be generic types of responses in situations characterized by difficult choices in organizations, regardless of context. For example, in an EA context loyalty means to comply with the EA policies and blueprints, voice means to actively oppose or challenge the policies, and exit means to ignore it. If employees are loyal to an initiative, for 
example an EA initiative, the implementation of the initiative can be done with little resistance and fuzz. However, if employees prefer to race a voice and start a dialogue with EA, the implementation requires more work. The exit option means that no communication exists between the initiative and the people that are affected by the initiative. An exit also means that less is learned for all parties because "the exit option is ineffective in alerting management to its failings" [15] and the employees remain uninformed about what is going on.

Second, we take all three responses to be legitimate, i.e. they are rational and sensible choices, depending on the individual's situation and options. While the normative EA literature $[3,4]$ is focusing on compliance (and deviances from it), we believe that voice and exit are frequently happening in many organizations, and that the governance and EA literature needs to deal with these phenomena, not just trying to outlaw them. Moreover, we argue that dealing constructively with voice and exit might be exactly what the EA field needs to overcome its current crisis.

\section{Method}

The study was conducted at a governmental agency (hereafter referred to as the Agency) being accountable for long-term planning of a national transport system, including responsibility for the national railway system and the state road network. Historically, the Agency has been responsible the country's roads and rails, including all physical structures connected to them. However, lately this responsibility has broadened to include digital infrastructures connected to the country's transportation systems. Digitization of the transportation system and the digitalization of the Agency in general have grown to be a major concern, i.e. focusing on collecting, manipulating and distributing data to a diverse set of internal and external stakeholders. Stakeholders include all people using the infrastructure of transportation, ranging from big logistic and transportation companies to people living on the countryside and the disabled. Being a governmental agency they have developed a vision that expresses their long-term goal of "everybody arrives smoothly, the green and safe way". The digitalization of the Agency is a mean to reach their vision. Consequently, in an attempt to become a modern government, they take digitalization seriously.

\subsection{Data collection}

The data collection rests on three main collecting methods; semi-structured interviews, focus group discussions and written documentation [30, 31]. The semi-structured interviews focused on EA coupled with the three different projects, but also on how the agency handled information technology from a more general perspective. In the period 2013-15 we conducted 8 interviews and 11 focus group sessions. People that were interviewed were people involved in different EA projects affected by the EA guidelines created by the newly established EA initiative.

The focus group discussions improved our understanding of each project and gave us insights and new perspectives of the projects, and about the EA initiative at the Agency. All the people we interviewed individually were also part of at least two focus group workshops. The other participants in the focus groups were people directly or indirectly involved in either the EA initiative or the three different projects. The focus groups were all recorded and summaries of the focus group discussions were documented. The EA initiative was well documented, and relevant plans and reports were collected continuously throughout the data collection phase.

The interviews and the focus groups were all completed before the analysis of the empirical data started.

\subsection{Modes of Analysis of the Empirical Data}

Our approach was based on grounded principles [32] where we iteratively search for patterns in the empirical data. The analysis started with establishing a chronology and identifying the main themes and trends [33] for each project. This assisted us in getting a better understanding of the context we studied. For example, we identified problems the project teams faced, recognized what the project wanted to accomplish, acknowledged a project's position and reputation within the Agency, and distinguished current topics under discussion in the project. The semi-structured interviews assisted us with details, the workshop discussions gave us an overview, and the documentation often confirmed our interpretations of the interviews and discussions, or gave us more detailed information. All the details were written down in a table to keep track of everything. We continued our analysis by developing data displays [33] to find patterns in the empirical data. When analyzing the empirical data we identified "golden nuggets" [34] that drew our attention and that we decided to focus on more in detail. These "nuggets" concerned how and why the different projects responded to the EA initiative.

Drawing on the first analysis, it was possible to identify different responses to the EA initiative. Each response was analyzed in depth; we mapped how the downward communication was conducted, how the project team interpreted and how it responded. We also 
tracked whether the response was registered by the EA Group.

\section{Empirical findings}

Our findings describe and analyze the interplay between the central EA initiative and the three projects.

\subsection{The EA initiative}

In 2010, a decision was made to start a project that focused on enterprise architecture. Many existing systems overlapped in functionality or output, lacked in consistency or had bad data quality. To overcome the situation the EA initiative aimed to develop an enterprise architecture that would help the Agency's capability to "create IT-solutions that support the organization and the efficiency challenges, to steer so that different groups and projects within the agency pull together, create IT-solutions that enable better management of common requirements, to manage information and data in an efficient way, to use common and recyclable solutions rather than local solutions, to discourage overlapping initiatives that limit the challenge to achieve set economical goals for usage of IT'.

Previously, there had been no overall plan for the development of IT solutions. Several goals were therefore set for the EA initiative, including the most important goals of moving focus "from product- and application to agency- and information, when procurement of IT solution should recycling and standardization be pursued, information should be treated as one strategic resource and should therefore be managed as a valuable resource, IT solutions should have a low grade of unnecessary duplication, the focus should be on integration and information management with high accessibility and reliability". To fulfil set goals, gap-analysis was conducted and action plans were developed.

The EA team started with asking strategic questions of how to continue the development of different IT solutions, instead of telling people what to do. This slowly improved the awareness of the situation within the organization and made people more open to listen to their messages. It became clear after a while that the EA project was more than a project with a definite deadline. An EA group was therefore established and included in the central unit of IT. The group worked with short- and long-term strategies. For one, some of the suppliers they have to work with will supply the Agency with IT systems that will be used until 2030. It is therefore essential that guidelines and directions are open enough for the unknown future but at the same time specific enough to be used as guidance in ongoing projects. The EA group develops documentation that supports and guides the Agency and the different ongoing IT projects. With much energy and focus is the group guiding the Agency in its digitalization journey by reaching out in the organization and communicating their developed guidelines and directions.

\subsection{Project 1: Facility}

The Facility project aimed to structure and manage facility information, that is, information connected to all facilities included in the national road and rail infrastructure. There were a large number of stakeholders, both internally in the organization as well as external partners interested in, or require, this information to be able to plan for current and future traffic. One identified challenge was that there were often one IT solutions for each kind of information, type of facility, area of interest, geographical position and more. In other words, there were many silo systems, each developed for a specific purpose for a specific group of people. A recent scanning counted more than 40 different solutions included in the IT architecture for planning traffic and none of them were considered as the owner of master data. In addition, the necessity to combine information from different IT solutions to be able to plan was yet another factor to manage.

Consequently, there was a need to get an overview and organize all the different solutions to (i) being able to handle information concerning facilities in a structured way, to receive and enter information. (ii) find a way to manage information in a unified way of working instead of silo oriented, and (iii) enable all (known) stakeholders to acquire information when wanted. Challenges connected to the project were not only many silo solutions; the quality of the information was also questionable. For example, some information was missing or incomplete.

Another great challenge was that the project was supposed to implement changes simultaneously as all systems were in use 24/7. As expressed by an IT architect involved in the Facility project; "We need to rebuild the factory while the factory is running". Different organizational units within the Agency were dependent on the information included in the Facility project along with different dependencies between other system solutions. Consequently, changes in one IT system may have effects in other IT systems or on the information required for planning a certain traffic situation.

Since the general EA initiative was still in its early stages, little support from overall strategies existed and there was an uncertainty about what guidelines to follow within the project. One manager with the responsibility 
for the overall architecture of the project started to look for documentation that would guide him on how to proceed. He found some documentation but he also established a direct contact with the EA group and got a person from EA assigned to the project and started a dialogue.

Giving information about their situation to EA group assisted the EA architects in developing guidelines. In this way, the project complied with EA strategies and aligned with guidelines provided from the EA group. This means that the outcome of the Facility project was not only an IT solution for this specific project, but also an example of the organization's EA strategy in general. As an outcome of the co-operation and dialogue with the EA group, a decision to develop an integration platform that could facilitate information exchange between different systems and stakeholders was started.

\subsection{Project 2: Billing}

The Billing project had two goals; (i) to invoice the railway companies using the national network, and thus finance parts of the Agency, and (ii) to be used as a mean to influence on the behavior of the railway companies through pricing policies.

When trains use the rail, and connected infrastructure, the train companies pay a fee dependent on different factors. These factors include the train itself, how much it weighs, how long it is, how old it is, how the rail is used, from where the train is going to where, the time of the day it is going, the areas it is passing through etc.

The process to calculate the fee and then send out the invoice and receive payments affected different organizational units within the Agency. Each group had its own IT system with some elements required for billing. However, the various IT systems were not developed for the billing process but had some other main purpose. This meant that the data entered into a system was designed for a specific purpose but was also used for calculating a fee. Consequently, the systems included in the process might have incomplete or incorrect data required for fee calculation. In addition, the people working with the systems were not always aware that the data they entered, was being used for fee calculation. This sometimes occurred when systems were changed and the billing team was excluded from the information loop. This was an important issue since the organization had to, by law, follow regulations for billing and if the fee was wrong the Agency broke the law.

Since the billing process included several organizational units, there was no natural owner of the process. The project team working on establishing a process for the billing had limited power to influence what was being done to a specific system used by another organizational group. This was frustrating for at least two reasons. First, they had no incentives to use for people handling information required for billing, and second, they had no power to make any technological adjustments on any systems included in the billing process.

Yet, although the project had limited possibilities to influence different systems and people, the team follow the provided EA guidelines when working with the billing process. They focused on negotiating how to improve the process without intruding on someone else's space too much and at the same time implementing EA guidelines and directives. The project was dependent on other employees' goodwill to help the project by doing adjustments in different required systems and assist with necessary support. The project's position as distanced from the different IT systems and groups across the organization, resulted in a rather isolated response both towards the people involved in the process but also to the EA initiative. The loyalty from the project to both sides, the EA and the people involved in the billing process, was not recognized even though the project was successfully implemented.

\subsection{Project 3: API}

The API project was a small project run by a few enthusiasts with scarce resources. The main goal of the project was to make data available for third party developers who want to develop an "app" based on open data provided by the Agency. The origin of the project was that information provided to train stations, used for calling out arrivals of trains, was craved for by third party developers. The developers wanted to use the data for apps that could solve customer needs. However, there was no possibility for these developers to access these data except for "scraping" existing official websites displaying the data. The problem was that if the website changed, the application would not work anymore. At one time, an application caused fatal errors on a website because of an endless loop of requests to the website from the application.

As a result of these problems a new project was initiated called API was initiated, consisting of 3-5 people. It started out as a test, and at the same time the Agency tried to understand what kind of data was needed, how to provide the data and with what means. In December of 2012 it was decided that API's (Application Programming Interface) should be developed and openly published for any external stakeholder to use.

The API was open-ended and had no specific information or systems connected to it, it simply allows developers to ask for specific information available in 
different systems. This solution allowed for flexibility from the Agency perspective as well as from the developers' perspective. The basic logic of the solution followed an ETL (Extract, Transfer and Load) process. That is, it extracted data from different sources within the Agency, these data were transformed into a proper format that complied with the API and was then downloaded into an object-oriented database. The agency did not have to consider if a certain API belonged to a specific system and the developers could use the API to ask for specific data since the API was not pre-specified.

However, the API project required some technological solutions that were not available within the Agency. Also, the solutions were not included in the pre-specified solution lists provided by the EA group. Instead of discussing this with the EA, the project simply acquired the technology they needed. The technology they used were often based on open source solutions and well established in the open innovation community. The small project worked independently and more or less in isolation, having no change requirements on existing systems. They could continue their work because they adjusted their solution to existing solutions, not involving or communicating with people inside the Agency more than necessary. Instead, they had much communication with third party developers to understand their needs and requirements. The API team was not well known within the agency because they did not make much noise about how and what they did. Instead, they continued their work in their own way like rebels. They bought what they needed, communicated with third party developers and the open source community and developed API's according to their own experience and knowledge, not asking for, or receiving, advice from the EA group.

\subsection{Summary of findings}

Although the three projects were expected to comply with the EA initiative we can see three different types of responses to the enterprise architecture initiative. The Facility project cooperated with the EA group, by having a dedicated EA person involved in the project and together co-developing EA guidelines. In opposite, the API project was not paying much attention to EA guidelines and directives. Instead, the project was making its own rules based on the open data community and using open source solutions not included in the EA directives. The Billing project followed existing guidelines loyally even though they did not make any technological changes, but established a crossorganizational process. Table 1 shows an overview of the different projects and how the communication worked for each project.
Table 1 Project responses

\begin{tabular}{|l|l|l|l|}
\hline Project & $\begin{array}{l}\text { Downward } \\
\text { governance }\end{array}$ & $\begin{array}{l}\text { Upward } \\
\text { Feedback }\end{array}$ & Chosen response \\
\hline Facility & Frequent & Frequent & $\begin{array}{l}\text { Critical } \\
\text { compliance }\end{array}$ \\
\hline Billing & One-way & None & $\begin{array}{l}\text { Loyal, but } \\
\text { isolated }\end{array}$ \\
\hline API & None & None & Rebel \\
\hline
\end{tabular}

What we can see are different mechanisms mediating between top-down and bottom-up projects connected to the EA initiative. Mechanisms mediating a top-down project (Facility) are based on communication and include alignment, control and holistic perspective and responds with further development of EA. There was a two-way communication between the EA's and Facility and they have a common goal of reducing complexity and dependencies by developing new solutions, for example an integration platform.

The bottom-up project (API) remains independent, flexible and agile with little influence on, and from, EA. Instead they rely on the open innovation community that exists outside of the Agency. The API project can work this way because their solution was based on extraction of data, and have no consequences for other systems. There was limited communication, between the EA initiative and the project because the API project was small and does not have any effects on other systems. Mediating mechanisms are non-existent.

The "in-between" project, the Billing project, was loyal but with little influence in either direction. In other words, it was one-way communication where the Billing project loyally applied the directives the best they could, but gave little feedback. The mediating mechanism that makes the project accomplish its commitment was the establishment of new social structures throughout the silo-based organization. The Billing-project was dependent on the relations to people responsible for, or working with, the different systems that are included in the billing process and their good will of making necessary adjustments.

\section{Discussion}

Although Hirschman's theory of exit, voice and loyalty focuses on responses to decline in organizations, we find it useful as sensitizing concepts [18] to understand the studied EA initiative and projects within the Agency.

In this section, we discuss the results in the light of Hirschman's terms of loyalty, voice and exit offering three alternative responses to EA initiatives. First, a project can choose to be loyal to the EA initiative, i.e. to 
follow the EA guidelines, assuming that they are sensible and helpful. Second, a project can, if the project is not satisfied with implications of the EA guidelines, choose to voice a protest, i.e. to engage in an internal discussion on the principles or implementation. Or, third, a project can ignore the EA initiative ("exit"), and design solutions that are independent of, or in conflict with, EA. Our position is not to regard the three different responses as problems to be solved, but rather to identify them as opportunities offered to the EA team, and to EA research. Our argument is summarized in Table 2.

Table 1 Opportunities for the EA team

\begin{tabular}{|l|l|l|}
\hline $\begin{array}{l}\text { Hirschman' } \\
\text { s concepts }\end{array}$ & $\begin{array}{l}\text { Mediating } \\
\text { mechanism }\end{array}$ & $\begin{array}{l}\text { Opportunities } \\
\text { for EA team }\end{array}$ \\
\hline Voice & $\begin{array}{l}\text { Alignment and } \\
\text { control based on } \\
\text { communication }\end{array}$ & $\begin{array}{l}\text { Co-develop EA } \\
\text { strategy }\end{array}$ \\
\hline Loyalty & $\begin{array}{l}\text { New social } \\
\text { structures and } \\
\text { people's good } \\
\text { will }\end{array}$ & $\begin{array}{l}\text { Understand } \\
\text { local innovation }\end{array}$ \\
\hline Exit & $\begin{array}{l}\text { Independency and } \\
\text { flexibility relying } \\
\text { on open } \\
\text { community }\end{array}$ & $\begin{array}{l}\text { Develop } \\
\text { generic/ } \\
\text { standardized } \\
\text { interfaces }\end{array}$ \\
\hline
\end{tabular}

\subsection{Voice - and Co-develop Strategies}

The response in the Facility project is characterized by critical compliance; i.e. the project team accepts the EA authority and overall policy, but disagrees in several specific matters that are important for the project.

As we observed in the Facility project, they perceived the guidelines as too vague and not sufficiently specific. Facility was expected to integrate a number of existing systems, and many questions arose that were not dealt with by the policies. Fortunately, the EA team responded wisely to this critique by two measures: they made one enterprise architect a permanent part of the project team, and they decided to use the project as a learning arena. With continuous twoway communication, listening to each other, discussing and negotiating, new EA directives were developed. Although this can be a slow process, especially if many people are involved, it is well controlled and the outcome is holistic.

Overall, this solution worked well, and illustrates a salient point. The recommended governance mechanisms, such as Project Impact Assessments and Architecture Compliance reviews to ensure compliance tend to be mostly top-down and focused on control. However, the organizational learning cycle of which a successful EA initiative depends on requires frequent feedback from the on-going projects. That is, we recognize how bottom-up communication, listening and communicating with on-going projects, is valuable when developing EA strategies for an organization.

One aspect of having an architect as part of the project team deserves a comment, because the architect may feel somewhat trapped between being loyal to the EA group or the project manager. Van der Raadt argued that "In order to perform their tasks properly, architects should not be subordinate to project managers who have to defend the planning and budget of individual solution development projects" (p.22). In practice, this is incongruent with the way projects are usually run, and most project managers would protest, arguing that a project needs to balance various requirements [15].

\subsection{Loyal - and Understand Local Innovation}

The normative EA literature assumes compliance with central policies, without going into depth of the necessary learning cycle [3]. This sentiment is usually shared by the EA group, who is often busy with the complex task of putting all the pieces together, and assessing new project initiatives. So, from the view of the EA group a project that is loyal to EA policies is just perfect.

However, one problematic issue with the loyalty approach is the lack of upwards feedback to the EA group, since the loyal project often will comply with the policies, and quietly solves its business and technical needs without much communication. The Billing project was an example of this response, where the project team worked in relative isolation.

What the EA Group misses in this case is the opportunity to understand how the project team deals with these policies. For example, in the Billing project we observed how the team found innovative solutions within the prescribed architecture. The Billing project worked hard to establish relations to people required to be included in the billing process. This highlights the necessity of connecting different groupings, more or less, connected and/or dependent to EA initiatives. This ought to be interesting input to the EA group, not only to widen the horizon for the EA and get input from different groupings within the company, but also because it is important for the success of an EA initiative that the architecture allows for local innovation. The project also illustrates how much can be done without little, or no, change in the technological architecture, but instead focusing on establishing new processes and changing social structures.

\subsection{Exit - and Develop Generic/Standardized Interfaces}


The API project chose to ignore the EA policies, and instead solved its needs by designing solutions that may conflict with them. There may be various reasons for this; for example, the project might feel that the EA policies are not relevant, or that there are organizational priorities that simply overrule the EA guidelines.

In the API project, we observed that the project chose to ignore the EA guidelines, and designed a quite innovative solution by implementing new technology (object oriented database), and bypassing existing systems. In their development, they looked at the open innovation community, learning and getting inspired from how and what they do. The EA group chose to ignore the project, maybe not intentionally, but still, there were no interest in the project and no communication between the EA group and the API project. This is, in our opinion, a pity. The potential, but lost, learning opportunity for the EA group is considerable: first, they could have learned how an innovative team used new technology, second, the EA people could look more outside of the agency and learn from external resources, as in this case, the open innovation community (an unconventional yet successful community). Third, they could have generalized their experience into developing guidelines, or designing, more general solutions, such as a platform for API interfaces.

Bloomberg [6] argued that future agile EA is dependent on more loosely coupled components and services, because nobody can predict the needs of the future, and local designers should be allowed to recombine elements innovatively. Thus, the rebel, but competent initiatives should be considered integrated in the overall EA efforts. This is not to say that anything goes, but that the EA group should focus on learning, not control.

\subsection{Contribution and Limitations}

We believe that the three responses discussed here, are not necessarily problems, but constructive inputs to a discipline in crisis. As Bloomberg [1, 6] argued, a key problem of EA is a general overemphasis on analysis and models, and a lack of agility and learning.

Our conclusion of this study, and contribution to the discipline, is threefold. First, we highlight, following Bloomberg's [1] suggestion, that iterative learning and frequent feedback is a prerequisite for a successful EA initiative. This communication includes listening to, and

\section{References}

[1] J. Bloomberg. (2014, 2nd of February). Is Enterprise Architecture Completely Broken? learning from, external resources, including informal groupings such as the open innovation community. By doing this, a possibility to learn about new and innovative solutions, might speed up the process, becoming more agile, instead of aiming for compliance from all parties. Second, the central EA team should be ambidextrous, exploiting and exploring, and learn from project responses, instead of trying to control them. This means to embrace the various responses from the projects, and accept a more heterogeneous architecture and a more agile governance approach than prescribed in the normative frameworks literature [3, 4]. Third, we want to emphasize that EA is as much about people as it is about technology. That is, only focusing on how to architecture the technology limits possibilities to succeed. Establishing new social structures enabling communication within and between groups is as important as connecting the groups with new technology. To the end, we acknowledge that there are many unsolved issues in the EA field.

\section{Concluding remarks}

Our investigation identified three generic response strategies to Enterprise Architecture initiatives; loyal (complying with EA guidelines), voice, (accepting EA authority, but communication disagreement on some aspects) and exit (ignoring the EA guidelines).

The three response types should not be seen as resistance to be overcome, but should serve as input to a discipline which is in need of renewal. Thus, we have chosen to explore the three responses as opportunities for the EA team to rethink their implementation approach. We suggest that EA initiatives actively take into account feedback from stakeholders and consider local responses as learning opportunities in the development of EA. The theoretical implication of our findings is that the EA research needs a more nuanced repertoire of actions for dealing with EA. Research focusing on stakeholders of EA and their response, actions and influence of EA, needs more attention and recognition.

In addition, we highlight the importance of mediating mechanisms that enable more communication. Research focusing on mediating mechanisms that are efficient and effective in regards to EA initiatives need more attention in future research.

[2] J. Zachman, "A Framework for Information Systems Architecture," IBM systems journal, vol. 26, pp. 276-292, 1987.

[3] O. Group. (2011, 2nd of February). TOGAF v 9.1.

[4] J. Ross, P. Weill, and D. Robertson, Enterprise Architecture as Strategy: Creating a Foundation for Business Execution: Harvard Business Press, 2006. 
[5] M. Lange, J. Mendling, and J. Recker, "An Empirical Analysis of the Factors and Measures of Enterprise Architecture Management Success," European Journal of Information Systems, 2015.

[6] J. Bloomberg. (2014, 2nd of February). Agile Enterprise Architecture Finally Crosses the Chasm.

[7] C. Schmidt and P. Buxmann, "Outcomes and Success Factors of Enterprise IT Architecture Management: Empirical Insight from the International Financial Services Industry," European Journal of Information Systems, vol. 20, pp. 168-185, 2011.

[8] D. Dang and S. Pekkola, "Root Causes of Enterprise Architecture Problems in the Public Sector," presented at the PACIS, Taiwan, 2016.

[9] P. Leonardi, "When Flexible Routines Meet Flexible Technologies: Affordance, Constraint, and the Imbrication of Human and Material Agencies," Management Information Systems Quarterly, vol. 35, pp. 147-167, 2011. [10] O. Volkoff, D. Strong, and M. Elmes, "Technological Embeddedness and Organizational Change," Organization Science, vol. 18, pp. 832-848, 2007.

[11] H. Jonkers, M. Lankhorst, H. ter Doest, F. Arbab, H. Bosma, and R. Wieringa, "Enterprise Architecture: Management Tool and Blueprint for the Organisation," Information Systems Frontiers, vol. 8, pp. 63-66, 2006.

[12] J. Bloomberg, The Agile Architecture Revolution: How Cloud Computing, REST-based SOA, and Mobile Computing are Changing Enterprise IT. Hoboken, New Jersey: John Wiley \& Sons, Inc., 2013.

[13] S. Brown, Software Architecture for Developers: Technical Leadership by Coding, Coaching, Collaboration, Architecture Sketching and Just Enough Up Front Design: Leanpub, 2015.

[14] I. Greener, "Theorising Path-Dependency: How Does History Come to Matter in Organisations?," Management Decision, vol. 40, pp. 614-619, 2002.

[15] A. Hirschman, Exit, Voice, and Loyalty: Responses to Decline in Firms, Organizations, and States. United States of America: Harvard university press, 1970.

[16] B. Van Der Raadt and H. Van Vliet, "Designing the Enterprise Architecture Function," in Quality of Software Architectures. Models and Architectures, S. Becker, F. PLasil, and R. 'Reussner, Eds., ed: Springer, 2008, pp. 103118.

[17] W. Orlikowski, "Using Technology and Constituting Structures: A Practice Lens for Studying Technology in Organizations," Organization Science, vol. 11, pp. 404-428, 2000.

[18] G. Bowen, "Grounded Theory and Sensitizing Concepts," International Journal of Qualitative Methods, vol. 5, pp. 12-23, 2008.

[19] M. Röglinger, M. Bolsinger, B. Häckel, and M. Walter, "How to Structure Business Transformation Projects: The Case of Infineon's Finance IT Roadmap," Journal of Information Technology Theory and Application (JITTA), vol. 17, p. 2, 2016.

[20] T. Tamm, P. Seddon, G. Shanks, and P. Reynolds, "How does Enterprise Architecture Add Value to Organisations?," Communications of the Association for Information Systems, vol. 28, pp. 141-168, 2011.
[21] M. Lange, J. Mendling, and J. Recker, "An Empirical Analysis of the Factors and Measures of Enterprise Architecture Management Success," European Journal of Information Systems, vol. 25, pp. 411-431, 2016. [22] A. Lindström, P. C. Johnson, E. Johansson, M. Ekstedt, and M. Simonsson, "A Survey on CIO Concerns Do Enterprise Architecture Frameworks Support Them?," Information Systems Frontiers, vol. 8, pp. 81-90, 2006.

[23] T. Graves, The Enterprise As Story: the Role of Narrative in Enterprise-Architecture: Tetradian, 2012.

[24] J. Horkoff, M. Jesusfeld, J. Ralyté, and D. Karagiannis, "Enterprise Modeling for Business Agility," Business Information System Engineering, 2016.

[25] A. Martin, "Enterprise IT Architecture in Large Federated Organizations: the Art of the Possible," Information Systems Management, vol. 29, pp. 137-147, 2012.

[26] P. Kemp and J. McManus, "Whither Enterprise Architecture?," ITNOW Computing Journal, vol. 51, pp. 20 21, 2009.

[27] J. Hoogervorst, "Enterprise Architecture: Enabling Integration, Agility and Change," International Journal of Cooperative Information Systems, vol. 13, pp. 213-233, 2004.

[28] M. Crossan, H. Lane, and R. White, "An Organizational Learning Framework: From Intuition to Institution," Academy of Management Review, vol. 24, pp. 522-537, 1999.

[29] B. Bygstad and N. Pedersen, "«Arkitektur handler om praktisk arbeid i organisasjonen, ikke en tegning» En forskningsagenda om IT-arkitekters utfordringer," in Nokobit, Bodø, 2012.

[30] M. Myers and M. Newman, "The Qualitative Interview in IS Research: Examining the Craft," Information and organization, vol. 17, pp. 2-26, 2007.

[31] J. Kitzinger, "Qualitative Research: Introducing Focus Groups," BMJ, vol. 311, pp. 299-302, 1995.

[32] K. Charmaz, Constructing Grounded Theory: A Practical Guide Through Qualitative Analysis: SAGE, 2006.

[33] M. B. Miles and A. M. Huberman, Qualitative Data Analysis, Second ed. California: Sage, 1994.

[34] B. Glaser and A. Strauss, The Discovery of Grounded Theory: Strategies for Qualitative Research, Seventh ed. New Brunswick and London: Aldine Transaction, 2012. 